\title{
DO ENTRETENIMENTO AOS ASSUNTOS INTERNACIONAIS: A PAZ MUNDIAL NAS PÁGINAS DA REVISTA O CRUZEIRO (1945-1953)
}

\author{
FROM ENTERTAINMENT TO INTERNATIONAL AFFAIRS: \\ WORLD PEACE ON THE PAGES OF THE MAGAZINE O CRUZEIRO \\ (1945-1953)
}

Edvaldo Correia Sotana'

RESUMO: O presente artigo visa a contribuir com os estudos ocupados com a história da imprensa escrita brasileira. Especificamente, pretendemos analisar o material jornalístico sobre a manutenção da paz mundial publicado pela revista O Cruzeiro entre os anos de 1945 e 1953. Atentaremos, também, para o processo de produção deste noticiário internacional e para os espaços utilizados para sua publicação. Além disso, objetivamos situar as reportagens de Luciano Carneiro e enfocar, principalmente, os escritos de Drew Pearson e Austregésilo Athayde. Com o texto, intencionamos demonstrar: a) o anticomunismo da revista $O$ Cruzeiro; b) a possibilidade de investigarmos o noticiário internacional em periódicos brasileiros; c) a importância de olharmos a posiçáo político-ideológica de periódicos voltados para o entretenimento.

Palavras-chave: O Cruzeiro; paz mundial; anticomunismo.

ABSTRACT: This article intends to contribute to the history of the Brazilian written press. Specifically, we intend to analyze the news World peacekeeping published by the magazine entitled $O$ Cruzeiro between the years of 1945 and 1953. We will search international news production process and the pages used for its publication. We will also research, texts by Luciano Carneiro, writings by Drew Pearson and Austregésilo Athayde. In this paper, we will demonstrate: a) the anticommunism of the magazine; b) Possibilities for researching international news in Brazilian journals; c) The importance of researching the political and ideological position of entertainment magazines

Key-words: O Cruzeiro; world peace; anticommunism.

1 Doutor em História pela Universidade Estadual Paulista Júlio de Mesquita Filho e Professor Adjunto da Universidade Federal do Mato Grosso do Sul (UFMS), Campus de Aquidauana. E-mail: sotana.ufms@gmail. com 
Nos anos 1920, algumas transformações principiavam na imprensa brasileira. O início de um incipiente processo de modernização ${ }^{2}$ e da atuação de empresários que formariam os primeiros conglomerados jornalísticos brasileiros são dois exemplos das modificaçóes; ambas, é claro, se estenderiam pelas décadas seguintes. Certamente, as iniciativas de Assis Chateaubriand impulsionaram muitas das alteraçóes experimentadas pela imprensa escrita brasileira entre as décadas de 1920 e 1950. No período, o empresário construiu o seu conglomerado jornalístico (MORAIS, 1994, 191). ${ }^{3}$ Até os anos 1950, dominou o cenário de cadeias ou redes jornalísticas no Brasil (BAHIA, 1971, p. 79). A gênese do seu conglomerado, no entanto, situa-se décadas antes. Como uma das suas primeiras açóes, resolveu adquirir a revista semanal ilustrada $O$ Cruzeiro.

Em 1928, a revista O Cruzeiro foi adquirida pelo grupo Diários Associados. Chatô tomou conhecimento de que o jornalista português Carlos Malheiros Dias planejava lançar uma revista de circulação nacional. Ficou sabendo, também, que a falta de dinheiro ameaçava o projeto. Interessado, entrou no negócio com a disposiçáo de indenizar Dias pela quantia financeira por ele empenhada na revista até aquele momento. E, para angariar recursos, Chateaubriand se dirigiu a Getúlio Vargas, à época ministro da Fazenda. Vale a pena atentar para a descrição do episódio feita por Fernando Morais:

A revista que ele descreveu para o ministro nada tinha a ver com a do plano de Malheiros Dias: a Cruzeiro de Chateaubriand era uma revista com papel de melhor qualidade, repleta de fotografias, contaria com os melhores articulistas e escritores do Brasil e do exterior, e assinaria todos os serviços estrangeiros de artigos e fotografias. Impressa em quatro cores pelo sistema de rotogravura, [...] seria semanal, com tiragem de 50 mil exemplares [...] que circulariam em todas as capitais e principais cidades do Brasil (MORAIS, 1994, p. 178).

Consta ainda que Vargas agilizou, junto ao Banco do Brasil e ao Banco da Província do Rio Grande do Sul, o empréstimo necessário para Chatô adquirir a revista e assim se despediu: "Vai comprar a nossa revista." (MORAIS, 1994, p. 179). Em que pese o

2 Há um consistente debate sobre o processo de modernização da imprensa brasileira. Ver, por exemplo, as diferentes posiçôes expostas por Sodré (1966), Ribeiro (2007) e Barbosa (2007). Em síntese, ampliação do espaço para a veiculação de anúncios, implantaçáo de um padrão empresarial de gestão caracterizado por formas de gerência mais impessoais, adoção de estruturas administrativas que pretendiam racionalizar o processo de produção/ circulação do material jornalístico e formalização de uma série de procedimentos de redação que incidiam, principalmente, sobre as notas e reportagens, gêneros jornalísticos considerados informativos (o lide, a pirâmide invertida, o copidesque e os manuais de redação) são alguns exemplos das modificaçóes implantadas. A parte gráfica dos jornais também se transformou com o desenvolvimento de novas técnicas de redação, a utilização de um novo conceito de fotojornalismo e a associação entre imagens e textos. Desse modo, temos um processo de transição do jornalismo político-literário para o empresarial, mudança marcada pela intenção — segundo os próprios impressos - de produzir o jornalismo neutro, objetivo e distante dos partidos e grupos políticos, aprofundada, muito provavelmente, pelo surgimento dos jornais Tribuna da Imprensa (1949) e Última Hora (1951), bem como pelas reformas redacionais, gráficas e editoriais do Diário Carioca (1950) e do Jornal do Brasil (1956) (RIBEIRO, 2006, pp. 427-8). Consideramos, assim, como um processo a modernização da imprensa escrita brasileira, iniciado nas décadas de 1920 e 1930 e aprofundado nos anos 1950. A despeito dele, é nossa hipótese de pesquisa - tanto aqui quanto em outros trabalhos - que as revistas e os jornais não deixaram de atuar no campo político brasileiro na recente história do Brasil Republicano, como bem ilustra o que ocorreu na oposição a João Goulart e no golpe civil militar de 1964, na eleição e impeachment de Fernando Collor, assim como no golpe contra Dilma ou na perseguição a Lula.

Cf.: Carneiro (1999) e Wainberg (1997). 
carregar nas tintas — expediente muito particular da biografia —, a passagem alude à temática central do presente artigo, a relação entre $O$ Cruzeiro e a política.

Alguns anos foram necessários para a consolidação do periódico no mercado brasileiro. Ao longo da década de 1940, transformou-se na "maior revista de toda a América Latina, até viver seu apogeu absoluto no início dos anos 50". (ACCIOLY NETO, 1998, p. 89).

Apesar de não dedicar amplo espaço ao jornalismo internacional, como fizera alguns jornais nacionais, O Cruzeiro tratou de temas relativos aos embates marcantes da conjuntura internacional nas décadas de 1940 e 1950. Guerra e paz figuraram, assim, em editoriais, colunas e artigos assinados, mas também no espaço reservado para foto-reportagens nos anos posteriores a Segunda Guerra Mundial.

Vale observar que poucas revistas se dedicavam aos informes ou reflexóes sobre "relaçóes ou assuntos internacionais" nos anos 1940 e 1950. Essa preocupação temática se tornou mais freqüente durante os anos 1960, sobretudo em decorrência das iniciativas empreendidas pelas revistas Veja e Visão. Ambas procuraram formar equipes de redatores especializados em política externa e assuntos internacionais (NATALI, 2004, pp. 43-4). Ainda assim, o noticiário internacional figurava nas páginas de $O$ Cruzeiro. Portanto, pretendemos analisar o material jornalístico sobre a manutenção da paz mundial veiculado nas páginas da revista $O$ Cruzeiro entre os anos de 1945 e 1953, assim como os espaços jornalísticos utilizados para sua veiculação e aspectos do processo de produção notícia. ${ }^{4}$ Em meio a este noticiário internacional, situaremos as reportagens de Luciano Carneiro e enfocaremos, também, os escritos de Drew Pearson e Austregésilo Athayde.

Importa salientar que a coluna intitulada Carrossel do Mundo, escrita por Drew Pearson e publicada na revista $O$ Cruzeiro, entre 1947 e 1963, foi tomada como objeto de estudo pelo pesquisador Fábio Fiore de Aguiar (2015). Na sua dissertaçáo de mestrado, Aguiar não discutiu todo o período, mas somente o material publicado entre 1951 e 1954, recorte este que permite diferir nosso artigo do seu estudo. O pesquisador procurou tomar a coluna como:

[... [ uma tática de Assis Chateaubriand de apoio ao capital estrangeiro e ao livre mercado, dedicando a coluna de Drew Pearson como propagadora de ideias anticomunistas no Brasil, medida favorável ao projeto de Defesa Nacional dos EUA que pretendia conter o avanço da influência soviética. Nossa abordagem irá contrapor a ideia de Defesa Hemisférica Ocidental, que possui sua base sedimentada no anticomunismo, com o nacionalismo emanado do governo Vargas (1951-1954). (AGUIAR, F. 2015, p. 8).

Convém registrar, igualmente, que pesquisadores brasileiros tem se ocupado em estudar o jornalismo internacional. João Batista Natali (2004), Sidney Garambone (2003), Verônica Goyzueta \& Thierry Ogier (2003), Andreia Carolina S. Peres (2005), Orivaldo Biagi (2001), Igor Marx Freire Ferreira Lima e Silva (2006), Fhoutine Marie Reis Souto (2009), Pedro Aguiar (2008 e 2009) e Rafael Henrique Antunes (2013) são exemplos de

4 A pesquisa com a revista O Cruzeiro (1945-1953) foi realizada em dois arquivos distintos. O acervo correspondente ao período 1945-1949 foi consultado na Biblioteca e Centro de Documentação do Museu de Arte de São Paulo Assis Chateaubriand. Já o período compreendido entre 1950 e 1953 foi realizado CEDAP - UNESP/Assis. 
estudiosos que abordam, mais detidamente, o noticiário acerca de acontecimentos internacionais veiculado pela imprensa escrita brasileira. Trabalhos que fornecem panorama mais geral da imprensa nacional também salpicam informaçóes em suas páginas. É o caso dos estudos de Barbosa (2007) e Ribeiro (2007). Uma lacuna, no entanto, caracteriza tanto os estudos ocupados com os processos de produção e veiculação do noticiário internacional quando as obras mais gerais que pontuam algumas informaçóes em meio à descrição da história do jornalismo. Pouco foi escrito sobre o jornalismo internacional produzido por periódicos brasileiros no início da Guerra Fria.5 Constatação que justifica o interesse em discutir a paz mundial nas páginas de O Cruzeiro nos anos iniciais da Guerra Fria.

Examinar trabalhos acadêmicos acerca da revista $O$ Cruzeiro reforça nossa percepção. É fato que o periódico despertou interesse de diversos pesquisadores. Alguns trabalhos acadêmicos já enfocaram, por exemplo, a presença do fotojornalismo na revista (PEREGRINO, 1990; COSTA, 1992), a seção intitulada "Da mulher para a mulher" (COSTA, 2003), assim como a arte e a cultura no período da bossa nova (GAVA, 2003). Outro estudo tomou como objeto a imagem de Juscelino Kubitschek construída pela revista em reportagens, entrevistas, artigos e crônicas (AZEVEDO, 2004). É possível observar, no entanto, que as reportagens, colunas e artigos assinados sobre o cenário internacional configuram-se como material praticamente inexplorada pelos estudiosos.

Convém considerar, ainda, que as publicações periódicas constituem "rico manancial de fontes privilegiadas para historiadores", podem ser abordadas das mais diferentes formas (SIMÔES JUNIOR, 2006, p. 1) e atraem a atenção dos pesquisadores interessados em conhecer a produção intelectual de determinados períodos da nossa história. Uma revista como $\mathrm{O}$ Cruzeiro permite ao estudioso vislumbrar os temas de interesse da época, como eles foram abordados, quem eram seus atores e quais eram seus leitores (CORREA, 1999, p. 12). Por isso, indagamos: como a revista abordou o tema da paz mundial? Quem escreveu textos? Em quais espaços foram veiculados? Analisar o material ajuda a conhecer a posição política do periódico?

\section{O CRUZEIRO}

Nas décadas de 1940 e 1950, O Cruzeiro adquiriu grande potencial de circulação nacional, como sugere a evolução da sua tiragem. Em 1943, cada edição atingia onze mil exemplares. Já em 1950, o número subiu para cem mil exemplares. Quatro anos depois,

5 A maior parte do material aqui abordado foi publicada nos anos iniciais da Guerra Fria. Isto posto, a Guerra Fria se constitui num fenômeno complexo para os estudiosos ocupados com a História Contemporânea. Entre o período imediatamente posterior à Segunda Guerra Mundial e o fim da década de 1980, adeptos do capitalismo e do comunismo cultivaram embates ideológicos e tensóes diplomáticas. Disputas políticas, econômicas e militares tendo à frente EUA e URSS — deram a tônica do período. É preciso lembrar que existe um amplo debate sobre suas origens. Para maiores informações sobre o debate, consultar: Munhoz (2004). Sobre seu início, Vizentini (2000, pp. 198-204) ressaltou que o discurso proferido por Churchill transformou-se em "símbolo maior dos ventos da Guerra Fria”. De acordo com o autor, a rivalidade foi impulsionada, em 1947, pela proclamação da Doutrina Truman, pelo plano Marshall e pelo discurso em que Zadanov, entáo dirigente soviético, afirmou ser irredutível o antagonismo entre socialismo e capitalismo. 
chegou em 720 mil exemplares. Em 1957, sua tiragem alcançou a impressionante marca de 887 mil exemplares (CARNEIRO, 1999, p. 335). É certo que esses dados não representam o potencial de venda ou o número de leitores do periódico. Os usos, os manuseios, as formas de apropriação e de leitura dessa revista não podem ser expressos unicamente pela sua tiragem (CHARTIER, 2001, pp. 77-78). É muito provável, por exemplo, que cada exemplar publicado possuía mais do que um leitor.

Aos poucos, no entanto, a revista entrou em declínio. Em meados dos anos 1960, apresentava nítidos sinais de enfraquecimento em decorrência da presença da televisáo como meio de comunicação no Brasil. A revista também sofreu com a ampliaçáo do mercado de periódicos (MARTINS; DE LUCA, 2006, p. 86). O Cruzeiro teve que enfrentar, por exemplo, a concorrência da Manchete que, já na segunda metade dos anos 1950, adotou a estratégia de contratar os jornalistas demitidos por Chateaubriand e, assim, aprimorar a sua qualidade gráfica para ficar cada vez mais "colorida, atraente e fácil de ler" (ANDRADE, CARDOSO, 2001, p. 247).

Para alguns estudiosos, no seu período áureo, o periódico consolidou sua penetração nos mais diversos espaços, pois tanto moradores de favelas, quanto parlamentares tinham acesso a essa publicaçáo (CARNEIRO, 1999, p. 340). Seu sucesso pode ser relacionado à adoção de uma linha editorial destinada ao público diversificado. Homens e mulheres de todas as classes sociais entravam em contato com a revista que desejava "ser popular". Essa motivação foi percebida por alguns estudiosos, tal como demonstra a passagem abaixo:

Por ser uma revista semanal de entretenimento, com muitas fotografias e títulos, representava a possibilidade de mais pessoas de uma mesma família, principalmente as mulheres, lerem ou folhearem às suas páginas de diversas maneiras. Sua linha editorial era precisa: queria ser popular a fim de fazer-se compreender por todos [...] (ANDRADE; CARDOSO, 2001, pp. 246-247)

Com conteúdo eclético, a revista publicou sobre índios hostis, discos voadores, guerras, revoluções, escândalos políticos, excursões proibidas, crimes mistérios (CARNEIRO, 1999, p. 334) e tratou periodicamente do mundo do rádio e dos esportes, assim como adotou o carnaval como assunto principal em pelo menos um mês do ano (ACCIOLY NETO, 1998, pp. 58-59). Além dos artigos assinados nas páginas iniciais, dos contos e das novelas, também veiculou "reportagens de atualidade" e a "crônica fixa de Raquel de Queiroz, chamada 'última página.”' (ACCIOLY NETO, op. cit. p. 134). Destinou, igualmente, páginas às festas ocorridas no Rio de Janeiro, as entrevistas com celebridades e aos "furos" de colunismo social (ACCIOLY NETO, op. cit. p. 71). Publicou a seção "De mulher para mulher", espaço que se tornou uma espécie de "consultório sentimental que recebia correspondências de todos os cantos do Brasil, como centenas de cartas por semana”. Além dessa seção, veiculou a coluna "Quebra-cabeças" e dedicou espaço para tratar da moda. Mas, certamente, foram as reportagens que se configuraram como "o sustentáculo de O Cruzeiro".

6 Cf: Letícia Arantes Jury (2017), especialmente sobre discurso crítico da cronista Rachel de Queiroz em sua coluna intitulada "Última Página", veiculada pela revista $O$ Cruzeiro, na década de cinquenta, configurando-se os textos como prática social. 
A introdução das "grandes reportagens" se transformou na sua principal marca. Quase sempre, os trabalhos produzidos em conjunto por repórteres e fotógrafos figuravam na abertura, no miolo e no fechamento da revista. Entremeando essas reportagens, figuravam fotos, seçóes fixas de entretenimento e utilidade geral, bem como as charges de Péricles ( $\mathrm{O}$ amigo da Onça) e Millor Fernandes (Pif-Paf). A introdução da rotogravura, a incorporação das práticas publicitárias ao texto e a utilização de modernas técnicas de divulgaçáo dos anúncios publicitários são algumas das inovaçóes experimentadas no processo de produção da revista. (CARNEIRO, 1999, p. 337).

Os equipamentos de impressão permitiram ao periódico ter um "importante papel na modernização da imprensa gráfica brasileira”, principalmente nos anos 1940 e 1950 (COSTA, 2003, p. 14). A revista atingiu, desse modo, um estágio de avanço técnico num período anterior aos demais órgãos vinculados aos Associados (BAHIA, 1971, 101). Para estudiosos como Nelson Werneck Sodré (1966, pp. 427-428), o periódico surgiu e se desenvolveu num momento em que a imprensa começou a adquirir formato empresarial e obteve um "grande avanço" material, técnico e administrativo. No período em tela, sua inegável qualidade técnica, a ampla utilização de fotografias e sua excelente rede de distribuição foram fundamentais para consolidá-la como maior revista ilustrada do país (ANDRADE; CARDOSO, 2001, p. 246).

\section{LANCES DA POLÍTICA INTERNA}

Chateaubriand também utilizou a revista como "veículo divulgador de suas iniciativas, estampou matérias sobre as campanhas que patrocinava" e criou reportagens para focalizar "festejos e comemoraçóes, cujo único objetivo às vezes era agradar os poderosos” (ACCIOLY NETO, 1998, pp. 80-85). Em um período de transição do jornalismo opinativo para o modelo norte-americano de produção da notícia, que procurava se apresentar como objetivo, neutro e distante dos partidos ou grupos políticos (ABREU, 1996; BARBOSA, 2007; RIBEIRO, 2007), a revista $O$ Cruzeiro foi, em algumas ocasióes, apresentada como uma revista que "não era política", como o fez Accioly Neto, então diretor de redação, ao utilizar o artifício para escapar das perseguições impostas aos Diários Associados em razão do apoio de Assis Chateaubriand a Revolução Constitucionalista de $1932^{7}$ (CARNEIRO, 1999, pp. 331-333). Como indicou Fernando Moraes (1994, p. 263), a revista demonstrou clara preocupação em posicionar-se politicamente apenas nos momentos de intensa atuação política do seu proprietário:

Até $O$ Cruzeiro, que apesar do enorme prestígio continuava sendo uma revista dedicada aos faits divers, sem preocupaçóes políticas, acabaria entrando na campanha pela redemocratização, com uma reportagem de duas páginas cortadas pelo escandaloso título "Constituinte!". A crise política que se avizinhava acabaria transformando a modorrenta revista dedicada à família em um seminário ágil e politizado, que reservava suas primeiras e mais nobres páginas à cobertura dos fatos políticos da semana (MORAIS, 1994, p. 263). 
A despeito da participação política da Revolução Constitucionalista de 1932, O Cruzeiro não possuía como principal característica o "fazer político" declarado. Por isso, pode ser caracterizada como uma revista ilustrada com preocupaçóes voltadas para o entretenimento e a diversão dos leitores. É justamente neste ponto que reside nossa sugestâo: o "fazer político" e a posiçáo ideológica de $O$ Cruzeiro aparecem no material acerca da situação internacional, notadamente nos textos sobre as ameaças a manutençáo da paz mundial e as possibilidades de uma nova e destrutiva guerra no período imediatamente posterior a Segunda Guerra Mundial. Portanto, não é o texto jornalístico utilizado para jogar, de modo declarado e explicito, no tabuleiro da política interna que nos interessa, mas o material veiculado sobre o cenário internacional.

\section{AS REPORTAGENS DE LUCIANO CARNEIRO}

Dentre os repórteres da revista, Luciano Carneiro certamente possui lugar de destaque. Nascido em Fortaleza, em 1926, Carneiro cursou direito, na Faculdade de Direito da capital cearense, até o quarto ano, momento em que enveredou para o jornalismo e começou a fotografar para os periódicos Correio do Ceará e o Unitário. Ingressou na revista em 1948 e logo tratou das tensōes mundiais provocadas por situaçóes bélicas e das ameaças ao estabelecimento da paz. Conhecido por sua atuação como correspondente internacional e considerado pelos demais funcionários da revista como repórter com gosto para a aventura, Carneiro realizou a cobertura da Guerra da Coréia ${ }^{8}$ e enviou diversas matérias produzidas na linha de combate (ACCIOLY NETO, 1998, p. 121). A revista destacou que o "jovem repórter" era o único correspondente sul-americano na Coréia. Em princípios de fevereiro de 1951, o correspondente foi para o Japão e conseguiu autorização para seguir ao fronte de batalha. Durante algum tempo, acompanhou as tropas de infantaria das Naçóes Unidas. Nesse período, atuou em busca da notícia. O Cruzeiro evidenciou, igualmente, que Carneiro "jamais voltou para a sua base sem haver realizado a cobertura jornalística", pois sempre procurou escrever e fotografar na perigosa tarefa de correspondente de guerra. Além disso, também informou sobre a publicação de outras colaboraçóes enviadas pelo seu correspondente de guerra.

O Cruzeiro, ao mesmo tempo que revela, com orgulho a façanha desse jovem e agressivo repórter, anuncia para breve a publicação de suas sensacionais reportagens, não só no campo da guerra coreana, como em diversos outros setores importantes, dentro de um plano de trabalho jornalístico que abrange extensa área do Oriente. ${ }^{9}$

Sua atuação também abarcou as negociaçóes de paz realizadas na cidade sul-coreana de Kaensong, entre os meses de julho e setembro de 1951 (BIAGI, 2001, pp. 217-218). Numa típica reportagem fotográfica de algumas páginas, com um pequeno texto e muitas imagens, Carneiro preparou uma matéria ainda na cidade japonesa de Tóquio. ${ }^{10} \mathrm{~A}$

8 Cf.: Alves (2007).

9 O CRUZEIRO. Missão cumprida. 14 abr. 1951, p. 36.

10 O CRUZEIRO. Conferência sem paz. 22 set. 1951, pp. 76-82. 
paz também motivou outros repórteres a publicarem textos antes mesmo de Luciano Carneiro. As reportagens fotográficas da dupla famosa David Nasser e J. Manzon foram veiculadas ainda em 1945 e, depois, em 1947. ${ }^{11}$

Vale lembrar que os três produziram num período de valorização do próprio repórter como profissional do jornalismo. Como bem ressaltou Ribeiro (2007, pp. 318-319),

o repórter — agora com salários mais altos e com uma formação cultural melhor — tornou-se uma figura central no jornalismo. A valorização do repórter começou junto com a dos fotógrafos, com a expansão das revistas ilustradas, como O Cruzeiro e Manchete. Havia repórteres bastante populares e disputados a peso de ouro pelas empresas jornalísticas. Talvez o exemplo mais emblemático deste tipo de profissional tenha sido David Nasser, que junto com Jean Manzon formou uma das mais famosas duplas de repórteres da época de ouro de O Cruzeiro.

Outro espaço impresso, no entanto, chamou nossa atençáo, a saber: a coluna do norte-americano Drew Pearson. ${ }^{12}$

\section{COLUNISMO NORTE-AMERICANO}

A partir de 1947, Drew Pearson passou a publicar periodicamente um artigo de fundo no periódico brasileiro. $\mathrm{O}$ articulista estrangeiro foi apresentado como conhecedor da situaçáo internacional, tal como demonstra o breve texto publicado acima da sua primeira colaboração, na seção intitulada Carrossel do Mundo. Considerado pela revista como "um jornalista excepcional", Pearson também foi rotulado de "um dos maiores comentaristas americanos" e de "um dos mais profundos e autorizados conhecedores da política interna de Washington". ${ }^{13}$

Como articulista estrangeiro, acompanhou e descreveu os bastidores da Conferência Interamericana de Petrópolis, realizada em 1947. ${ }^{14}$ Também tratou da importância da elaboração de um plano Marshall para a América Latina, ${ }^{15}$ do potencial destrutivo da bomba

11 Id., O fim da guerra. 12 maio 1945, pp. 9-14; Neurose de guerra. 09 jun. 1945, pp. 9-14; Osvaldo Aranha na ONU. 05 jul. 1947, p. 9; O mundo em Petrópolis. 30 ago. 1947; Cidadão Truman. 20 set. 1947, pp. 9-13.

12 De acordo com a pesquisa de Aguiar (2015, p. 18) "Andrew Russell Pearson, mais conhecido como Drew Pearson, foi um jornalista norte-americano nascido em 1897 e falecido em 1969. Conhecido por sua polêmica coluna Washington Merry-Go-Round, na qual juntamente com Bob Allen, atacavam personalidades públicas e criavam polêmicas. Pearson era conhecido por sua militância anticomunista, foi um dos maiores polemistas da América." Ainda segundo Aguiar (2015, p. 14), na década de 1940, "já era conhecido do público brasileiro em decorrência da "Política de Boa Vizinhança" nos tempos da Segunda Guerra, foi o responsável por assinar essa coluna. À época dos esforços coletivos entre Brasil e Estados Unidos durante a guerra, Pearson juntamente com Bob Allen, possuíam um programa de rádio que divulgava propagandas favoráveis a Defesa Hemisférica na América Latina” Segundo Sotana (2010, p. 19) discutia as questóes internacionais na Folha da Manhã, na seçáo intitulada Carrossel de Washington". Na revista O Cruzeiro, publicou a coluna "Carrossel do Mundo" de 1947 a 1963.

13 O CRUZEIRO. Carroussel do Mundo. 26 jul. 1947, p. 16.

14 Id., 27 set. 1947.

15 Id., 13 maio 1948. 
atômica, ${ }^{16} \mathrm{da}$ Guerra da Coréia, ${ }^{17}$ das perspectivas de paz mundial ${ }^{18} \mathrm{e}$ das possibilidades de uma terceira guerra mundial. ${ }^{19}$ Náo obstante, afirmou que os russos preparavam uma guerra total, ${ }^{20}$ chegando a indicar que a Uniáo Soviética tentava "enganar os norte-americanos com essa possível paz!!! para se preparar para a guerra." ${ }^{21}$

Mais do que atribuir aos soviéticos o papel de provocadores de guerra, Pearson procurou demonstrar que a paz mundial poderia ser garantida apenas pelo governo norte-americano, como o fez ao comentar a situação de tensóes e embates em razão do desfecho do conflito da Coréia. Em texto anterior, Pearson externou, de modo cristalino, sua posiçáa político-ideológica. Apesar de parecer desatino, consta no artigo do estrangeiro que Getulio Vargas procurava se aliar ao comunismo para "se vingar do governo norte-americano." 22

Essa associação entre Vargas e o comunismo foi produzida num momento anterior as eleiçóes presidenciais de 1950. Embora não tenha declarado sua aversão ao nome de Vargas ou o apoio ao brigadeiro Eduardo Gomes, a revista vinculou um texto, produzido por um jornalista norte-americano, com críticas as atitudes do primeiro candidato. Desse modo, suas colaboraçóes não apenas tomaram a URSS como provocadora de guerra, mas também indicaram o comunismo internacional e o possível Governo Vargas como desencadeadores de tensôes e conflitos, além, é claro, de serem classificados como inimigos da paz e dos EUA. Este e outros artigos podem, entáo, ser considerados como instrumentos de luta no campo político brasileiro.

Ao assumir a presidência, Vargas náo foi objeto de criticas de Person, como demonstra Fábio Aguiar (2015, p. 82): "Mesmo não tendo criticado Vargas e sua política nacionaldesenvolvimentista, as publicaçóes de Pearson sempre foram de caráter anticomunista, democrática e liberal. A coluna de Pearson promoveu uma mentalidade anticomunista no Brasil." Outros articulistas, contudo, também contribuíram para propagar representaçôes da URSS como ameaça a paz mundial e ajudar a sedimentar o anticomunismo no Brasil.

\section{A PAZ MUNDIAL POR ARTICULISTAS BRASILEIROS}

Convém destacar outros articulistas que trataram da paz mundial nas páginas de O Cruzeiro. No período compreendido entre 1945 e 1953, pode-se indicar o seguinte quadro:

\footnotetext{
16 Id., 18 mar. 1950; 22 abr. 1950; 19 ago. 1950; 27 dez 1952; 07 fev. 1953; 02 maio 1953;

17 Id., 26 ago. 1950.

18 Id., 15 abr. 1950; 06 maio 1950; 15 dez. 1951.

19 Id., 10 fev. 1951.

20 Id., 17 abr. 1948; 25 mar. 1950.

21 Id., 16 maio 1953.

22 Id., 03 jun. 1950.
} 


\begin{tabular}{|c|c|}
\hline Colaboradores & Número de Artigos Assinados \\
\hline Teophilo de Andrade & 14 \\
\hline Austregésilo Athayde & 10 \\
\hline Frankilin Oliveira & 03 \\
\hline Raquel de Queiroz & 03 \\
\hline
\end{tabular}

Fonte: O Cruzeiro, 1945-1953.

Ainda que Teophilo de Andrade tenha publicado um número maior de artigos, parece pertinente observarmos as produçóes de Austregésilo Athayde. Primeiramente, em função do limite de páginas do presente artigo para tratar dos quatro articulistas. Além disso, por aparecerem regularmente na quinta página do periódico, enquanto os textos de Andrade não possuíam um espaço fixo, já que figuravam nas páginas $30-31,{ }^{23} 32-33,{ }^{24} \mathrm{e}$ $45^{25} \mathrm{ou}$, ainda, entre as páginas 09 e $16 .{ }^{26}$ Athayde publicava, então, no espaço mais nobre do periódico (MORAIS, 1994, 262). Além disso, seus textos também interessam em função da sua proximidade com o proprietário dos Diários Associados. Com Chateaubriand, dividiu um garçonnière em Copacabana, participou da "Revolução Constitucionalista de 1932" e, por isso, também sofreu as perseguiçóes impostas pela ditadura varguista (MORAIS, 1994, p. 270/278/280-1/302). Em diversas atividades, chegou a representar o proprietário dos Diários Associados, tal como ocorreu nas reunióes do Conselho Nacional de Imprensa (SILVA, 2008, 94). Também foi responsável por diversas inovaçóes no jornalismo dos Associados. Nos EUA, buscou inspiração para a criação do "Jornal falado dos Diários Associados”, um jornal com meia hora diária de duração na Rádio Educativa. (MORAIS, 1994, p. 278).

É importante destacar que Austregésilo Athayde considerou a atuação dos líderes mundiais na Conferência de Paz, em Postdam, em 1945, como de “juízes sentenciando em nome dos mais altos interesses da justiça” ${ }^{27}$ Pouco depois, contudo, argumentou que o encontro náo promoveu a paz universal. Conforme registrou no seu artigo publicado em 1946: "A humanidade espera, pacientemente, há séculos, que se dê o milagre da paz que será, fora de dúvida, o maior de todos. A paz assegurada pela consciência universal do direito de todos e da justiça para cada um". ${ }^{28}$ Três meses depois, reconheceu a possibilidade de uma nova guerra em outro texto: "A imprensa universal está novamente cheia de temores de guerra. Movimentam-se as forças subterrâneas que desencadeiam os conflitos e primeiro que a espada entre em ação, faz-se o trabalho nas almas." ${ }^{29}$ No ano

23 O Cruzeiro. 17 nov. 1951.

24 Id., 01 dez. 1951.

25 Id., 16 fev. 1952.

26 Id., 02 nov. 1946.

27 O Cruzeiro. 18 ago. 1945.

28 Id., 05 jan. 1946.

29 Id., 06 abr. 1946. 
de 1947, produziu a seguinte formulação para tratar da Conferência de Petrópolis, do pan-americanismo e do Tratado Militar de Assistência Recíproca:

A família pan-americana reconhece e proclama a sua consanguinidade espiritual, os seus ideais idênticos, o mesmo amor a liberdade democrática e concluí daí um princípio jurídico na forma de obrigação livremente aceita de defende a sua maneira de vida no território intangível e na sagrada independência de todos. ${ }^{30}$

Assim sendo, é possível salientar que os artigos de Athayde mobilizavam um conjunto de elementos fundamentais no imaginário religioso. Milagre, temores, espada, trabalho nas almas, consanguinidade espiritual e sagrada independência não foram termos cunhados ao acaso. Ao contrário, signos e símbolos foram mobilizados na tentativa de produzir efeitos na batalha simbólica travada no campo político brasileiro. Athayde não se posicionou apenas contra os temores de guerra, mas também contra os temores provocados pelo comunismo no Brasil. Convém lembrar que, alguns meses depois, o registro eleitoral do Partido Comunista do Brasil fora cancelado e os parlamentares comunistas tiveram seus mandatos cassados. Portanto, com traços de religiosidade e conservadorismo, os artigos de Athayde cumpriram papel de destaque na propagação do anticomunismo no cenário nacional. Aprofundar a análise do anticomunismo presente na sua produção, em particular, e na revista $O$ Cruzeiro, em geral, sáo objetivos de uma pesquisa ainda a ser realizada.

Vale salientar que o anticomunismo foi um dos principais argumentos "a justificar e a provocar as intervençóes autoritárias mais significativas ocorridas no período republicano da história brasileira." $\mathrm{O}$ anticomunismo não pode, contudo, ser considerado homogêneo, principalmente por integrar ideários políticos táo díspares como dos reacionários, conservadores, liberais e esquerdistas (MOTTA, 2002, XXVI; p. 15). Não obstante, é possível ressaltar a vinculaçáo dos movimentos, instituiçôes ou militantes religiosos com uma postura política anticomunista. A Igreja Católica, por exemplo, considerava o comunismo como inimigo irreconciliável e, muito provavelmente, constituiu-se na instituição não-estatal "mais empenhada no combate aos comunistas ao longo do século XX" (MOTTA, 2002, p. 18).

Convém lembrar, por fim, que os textos de Athayde não foram os únicos da revista que combateram o comunismo e a URSS. O Cruzeiro também não foi o único órgáo da imprensa escrita brasileira com essa postura política e ideológica. Apenas para ilustrar, o trabalho acadêmico de Silva (2008) já indicou que os jornais $O$ Estado de S. Paulo, Correio da Manhã, Diário de São Paulo e Jornal do Brasil "mantiveram colunas específicas e publicaram artigos e entrevistas de líderes religiosos mundiais, os quais divulgavam suas ideias religiosas e posicionavam-se politicamente, sobretudo a partir do momento em que as discussōes acerca da Guerra Fria intensificavam-se." Ou, então, importa lembrar o estudo em que Mariani (1998) esquadrinha o anticomunismo na imprensa brasileira.

30 Id., 30 ago. 1947.

Do entretenimento aos assuntos internacionais: a paz mundial nas páginas da revista O Cruzeiro (1945-1953) 


\section{CONSIDERAÇÕES FINAIS}

O presente artigo procurou analisar, ainda que brevemente, o material jornalístico sobre a manutenção da paz mundial veiculado nas páginas da revista $O$ Cruzeiro entre os anos de 1945 e 1953, assim como os espaços jornalísticos utilizados para sua veiculaçáo e aspectos do processo de produção notícia na revista de Chatô. Intencionamos situar as reportagens de Luciano Carneiro, agente social, a propósito, que demanda pesquisas acadêmicas. Além dele, enfocamos os escritos de Drew Pearson e Austregésilo Athayde.

Com relação aos artigos de Austregésilo Athayde, percebemos que o articulista utiliza signos e símbolos próprios do catolicismo ou que se vinculam ao imaginário do período, expediente que ajuda a compreender a matriz anticomunista religiosa presente nas páginas da revista $O$ Cruzeiro. Os textos de Dreaw Pearson, por sua vez, denotam a admiraçáo do periódico com relaçáo ao jornalismo estadunidense, apresentam os Estados Unidos como responsáveis pela manutençáo da paz mundial e a URSS como naçáo belicosa que ameaça a pacificação do mundo num período inicial da chamada Guerra Fria.

Ainda que possa ser caracterizada como uma revista de entretenimento com opçáo editorial de articular imagens aos textos condensados, relegando ao segundo plano o jornalismo "de idéias e de opinióes", o anticomunismo figura nas páginas de O Cruzeiro e pode ser tomado como chave para o entendimento do seu fazer político. Olhar os assuntos internacionais foi nossa opçáo, especialmente o material sobre a manutençáo da paz no mundo e com relaçáo às possibilidades de uma nova guerra mundial (ou, de fato, um conflito que ocorreu como o da Coréia).

Cumpre lembrar que a imprensa brasileira experimentou um processo de transição do jornalismo político-literário para o empresarial, separando espaços para a opinião do material considerado informativo. Assim, órgãos passaram a se apresentar como neutros, objetivos e distantes dos grupos e partidos políticos. Apesar disso, atuaram no campo político brasileiro, como sugere o caso da aqui abordado.

A atuação política de um órgão impresso não está circunscrita a editoria política ou delimitada ao jogo partidário eleitoral. Um jornal ou uma revista detém instrumentos para gerar programas, análises, comentários, conceitos e acontecimentos, criando produtos políticos que representam o mundo social (BOURDIEU, 2000, pp. 164/170). Desse modo, atuar no jornalismo é uma "opção ideológica" em que definir "o que vai sair, como, com que destaque e com que favorecimento, corresponde a um ato de seleção e de exclusão". Assim, não parece possível "desvincular a notícia dos confrontos de interesses e de poderes de grupos dominantes da sociedade, nem da acepçáo de que haja qualquer possibilidade de se realizar um jornalismo objetivo", posto que um periódico sempre procura afirmar publicamente as opinióes e informaçóes de indivíduos ou grupos, bem como objetiva trabalhar na construção da notícia (MARCONDES FILHO, 1986, pp. 12-13).

Com o artigo, esperamos fomentar trabalhos acadêmicos ocupados com o noticiário internacional dos periódicos brasileiros. Desejamos, ainda, sugerir que um texto jornalístico náo pode ser compreendido unicamente a partir dele mesmo (BOURDIEU, 2000, p. 57). Cientes disso os pesquisadores precisam compreender as relaçóes sociais aos quais 
os periódicos estáo vinculados, assim como as pressóes que por vezes possam estar submetidos (BUSETTO, 2008, p. 16), isto é, o jogo de forças políticas e econômicas que, mesmo externas ao periódico, incidem tanto na forma quanto no conteúdo do que é publicado. Para além, perceber que as representaçóes veiculadas pela imprensa engendram práticas, alimentando, inclusive, ações que ajudam a instaurar regimes de exceção. Assim não ocorreu, diuturnamente, com a imprensa escrita brasileira, de circulação nacional ou local, na propagaçáo do anticomunismo que alimentou civis e militares na queda de João Goulart e na instauração do regime militar em 1964? Tanto lá quanto cá, a imprensa atuou politicamente, vide o modo como Dilma Rousseff e Luiz Inácio Lula da Silva foram (e sáo) tratados pelo jornaláo dos Marinho ou pela revista das páginas amarelas. Portanto, atuar no jornalismo é uma opção ideológica e olhar para o noticiário internacional pode ser uma maneira de investigarmos a posição político-ideológica de jornais e revistas, nunca desvinculados dos embates travados no mundo social. Enfim, foi o que tentamos demonstrar com a análise do material sobre a manutenção da paz mundial publicado pela revista $O$ Cruzeiro. 


\section{REFERÊNCIAS}

ABREU, Alzira Alves de. Os suplementos literários: os intelectuais e a imprensa nos anos 50.

In: . (Org.). A imprensa em transição. Rio de Janeiro: Fundação Getúlio Vargas, 1996.

AGUIAR, Pedro. Por uma história do jornalismo internacional no Brasil. In: ENCONTRO NACIONAL DE HISTÓRIA DA MÍDIA, 6., 2008 Anais... Niterói: Rede Alfredo de Carvalho, 2008. CD -ROM.

. Notas para uma história do jornalismo de agências. In: ENCONTRO NACIONAL DE HISTÓRIA DA MÍDIA, 7., 2009 Anais... Fortaleza: Rede Alfredo de Carvalho, 2008. Disponível em: <http://memoriadojornalismo.com.br/upload/imagem_0140603052729. pdf>. Acesso em: 10 jun. 2015.

AGUIAR, Fábio Fiore de. Carrossel do mundo: política internacional e defesa hemisférica na revista O Cruzeiro, por Drew Pearson (1951-1954). 108 f. Dissertação (Mestrado em História). Universidade Estadual de Londrina, Londrina, 2015.

ALVES, Wagner Camilo. Da Itália à Coréia: decisóes sobre ir ou não à guerra. Belo Horizonte: EdUFMG; Rio de Janeiro: IUPERJ, 2007.

ANDRADE, Ana Maria Ribeiro de; CARDOSO, José Leandro Rocha. Aconteceu, virou manchete. Revista Brasileira de História, São Paulo, v. 21, n. 41, pp. 243-264, 2001.

ANTUNES, Rafael Henrique. Pra não dizer que não se falou de flores: a repercussão da Revolução dos Cravos na imprensa brasileira, 1974-1976. 2013. 233 f. Dissertação (Mestrado em História). Faculdade de Ciências e Letras Universidade Estadual Paulista, Assis, 2013.

AZEVEDO, Teresa Cristina Nogueira. JK nas páginas de $\mathbf{O}$ Cruzeiro: a construção discursiva de um mito na imprensa. 128 f. Dissertação (Mestrado em Memória Social). Universidade Federal do Rio de Janeiro, Rio de Janeiro, 2004.

BARBOSA, Marialva. História Cultural da Imprensa: Brasil (1900-2000). Rio de Janeiro: Mauad, 2007.

BIAGI, Orivaldo. $\mathbf{O}$ imaginário e as guerras da imprensa: estudo das coberturas realizadas pela imprensa brasileira da Guerra da Coréia (1950-1953) e da Guerra do Vietná na sua chamada "fase americana" (1964-1973). 280 f. Tese. (Doutorado em História). Instituto de Filosofia e Ciências Humanas, Universidade Estadual de Campinas, Campinas, 2001.

BOURDIEU, Pierre. O poder simbólico. Rio de Janeiro. Bertrand Brasil, 2000.

BUSETTO, Áureo. A mídia brasileira como objeto da história política: perspectivas teóricas e fontes. In: SEBRIAN, Raphael Nunes et al. (Orgs.). Dimensóes da política na historiografia. Campinas: Pontes Editores, 2008.

CARNEIRO, Glauco. Brasil, primeiro: história dos Diários Associados. Brasília: Fundação Assis Chateaubriand, 1999. 
CHARTIER, Roger. Do livro à leitura. In: . (Org.). Práticas de leitura. 2. ed. São Paulo: Estação Liberdade, 2001.

CORREA, Ana Maria Martinez. Prefácio. In: LUCA, Tânia Regina de. A Revista do Brasil: um diagnóstico para a (N)ação. São Paulo: Unesp, 1999.

COSTA, Helouise Lima. Aprenda a ver as coisas: fotojornalismo e modernidade na revista "O Cruzeiro". 190 f. Dissertação. (Mestrado em Comunicação). Escola de Comunicação e Artes Visuais, Universidade de São Paulo, São Paulo, 1992.

COSTA, Maria Paula. “Da mulher para a mulher”: uma análise historiográfica do correio dos leitores da revista O Cruzeiro (1950-1963). 119 f. Dissertação (Mestrado em História). Faculdade de Ciências e Letras, Universidade Estadual Paulista, Assis, 2003.

GARAMBONE, Sidney. A primeira Guerra Mundial e a Imprensa Brasileira. Rio de Janeiro: Mauad, 2003.

GAVA, J. E. Momento bossa nova: arte, cultura e representaçóes sob os olhares da revista "O Cruzeiro". 215f. 2003. Tese (Doutorado em História). Faculdade de Ciências e Letras, Universidade Estadual Paulista, Assis, 2003.

GOYZUETA, Verônica \& OGIER, Thierry. Guerra e Imprensa: um olhar crítico da cobertura da Guerra do Iraque. São Paulo: Summus, 2003.

JURY, Letícia Arantes. Jornalismo como trincheira: o discurso crítico de Rachel de Queiroz na revista $\mathrm{O}$ Cruzeiro na década de cinquenta. 173 f. 2017. Dissertação. (Mestrado em Comunicação). Faculdade de Informação e Comunicação, Universidade Federal de Goiás, 2017. Disponível em: <http://repositorio.bc.ufg.br/tede/handle/tede/7198>. Acesso em: 20 jun. 2017.

HOBSBAWM, Eric. Era dos extremos: o breve século XX (1914-1991). 2. ed. São Paulo: C. ${ }^{\text {ia }}$ das Letras, 1995.

MARCONDES FILHO, Ciro. O capital da notícia. São Paulo: Ática, 1986.

MARIANI, Bethânia. O PCB e a imprensa. Rio de Janeiro/Campinas: Renavan/Unicamp, 1998.

MARTINS, Ana Luisa; LUCA, Tânia Regina de. Imprensa e Cidade. São Paulo: Unesp, 2006.

MORAIS, Fernando Morais. Chatô: o rei do Brasil, a vida de Assis Chateaubriand. São Paulo: C.ia das Letras, 1994.

MOTTA, Rodrigo Patto Sá. Em guarda contra o perigo vermelho: o anticomunismo no Brasil (1917-1964). São Paulo: Perspectiva/FAPESP, 2002.

MUNHOZ, Sidnei. Guerra Fria: um debate interpretativo. In: SILVA, Francisco Carlos Teixeira (Org.). O século sombrio: uma história geral do século XX. Rio de Janeiro: 1sevier/ Campus, 2004.

NATALI, João Batista. Jornalismo Internacional. São Paulo: Contexto, 2004. 
NETTO , Accioly. O império de papel: os bastidores de O Cruzeiro. Porto Alegre: Sulina, 1998.

PEREGRINO, Nadja Maria Fonseca. A Fotografia de reportagem: sua importância na revista O Cruzeiro (1944-1960). 163 f. Dissertação (Mestrado em Comunicação). Rio de Janeiro, Universidade Federal do Rio de Janeiro, Rio de Janeiro, 1990.

PERES, Andréa Carolina Schvartz. Enviado especial à ...: uma análise antropológica da cobertura da imprensa brasileira das guerras da ex-Iugoslávia (anos 90). 279 f. Dissertaçáo (Mestrado em Antropologia). Instituto de Filosofia e Ciências Humanas, Universidade Estadual de Campinas, 2005.

RIBEIRO, Ana Paula Goulart. Modernização e concentração: a imprensa carioca nos anos 1950 e 1970. In: NEVES, Lúcia Maria Bastos P.; MORÉL, Marco \& FERREIRA, Tania Maria Bessone da C. (Orgs.). História e imprensa: representaçóes culturais e práticas de poder. Rio de Janeiro: DP\&A/FAPERJ, 2006.

RIBEIRO, Ana Paula Goulart. Imprensa e História no Rio de Janeiro dos anos 1950. Rio de Janeiro: E-Papers, 2007.

RODRIGUES, João Paulo. Levante "Constitucionalista” de 1932 e a força da tradição: do confronto bélico à batalha pela memória (1932-1934). 320 f. 2009. Tese. (Doutorado em História). UNESP, Assis, 2009.

SILVA, Heber Ricardo da. A democracia impressa: transição do campo jornalístico e do político e a cassação do PCB nas páginas da grande imprensa, 1945-1948. 211 f. 2008. Dissertação (Mestrado em História). Faculdade de Ciências e Letras de Assis, UNESP, Assis, 2008.

SILVA, Igor Marx Freire Ferreira Lima e. Enquadramentos de Guerra: a cobertura do recente conflito no Iraque em dois jornais brasileiros. 169 f. 2006. Dissertação (Mestrado em Comunicação). Faculdade de Comunicação, Universidade de Brasília, Brasília, 2006.

SIMÔES JUNIOR, Álvaro Santos. Da literatura ao jornalismo: periódicos brasileiros do século XIX. Patrimônio e Memória, v. 2, n. 2, pp. 1-18, 2006.

SODRÉ, Nelson Werneck. História da imprensa no Brasil. São Paulo: Civilização Brasileira, 1966.

SOTANA, Edvaldo Correa. A paz sob suspeita: representaçóes jornalísticas sobre a manutenção da paz mundial, 1945-1953. 2010, 255 f. Tese (Doutorado em História). Faculdade de Ciências e Letras de Assis, Universidade Estadual Paulista Júlio de Mesquita Filho, Assis, 2010 .

SOUTO, Fhoutine Marie Reis. Depois da queda das torres: a cobertura jornalística do 11 de Setembro nos jornais Folha de S. Paulo e O Estado de S. Paulo. Ponto-e-Vírgula, n. 05, p. 230-235, 2009. Disponível em: <http://revistas.pucsp.br/index.php/pontoevirgula/ article/view/14090/10374>. Acesso em: 12 jun. 2015.

VIZENTINI, Paulo G. Fagundes. A Guerra Fria. In: REIS FILHOS, Daniel Aarão; 
FERREIRA, Jorge; ZENHA, Celeste. $\mathbf{O}$ século XX: o tempo das crises (revoluções, fascismos e guerras). Rio de Janeiro: Civilização Brasileira, 2000.

Artigo recebido em 28/06/2017 Artigo aceito em 18/11/2017 